\title{
Health information systems in the Islamic Republic of Iran: a case study in Kerman province
}

\author{
F. Zolala ${ }^{1,2}$
}

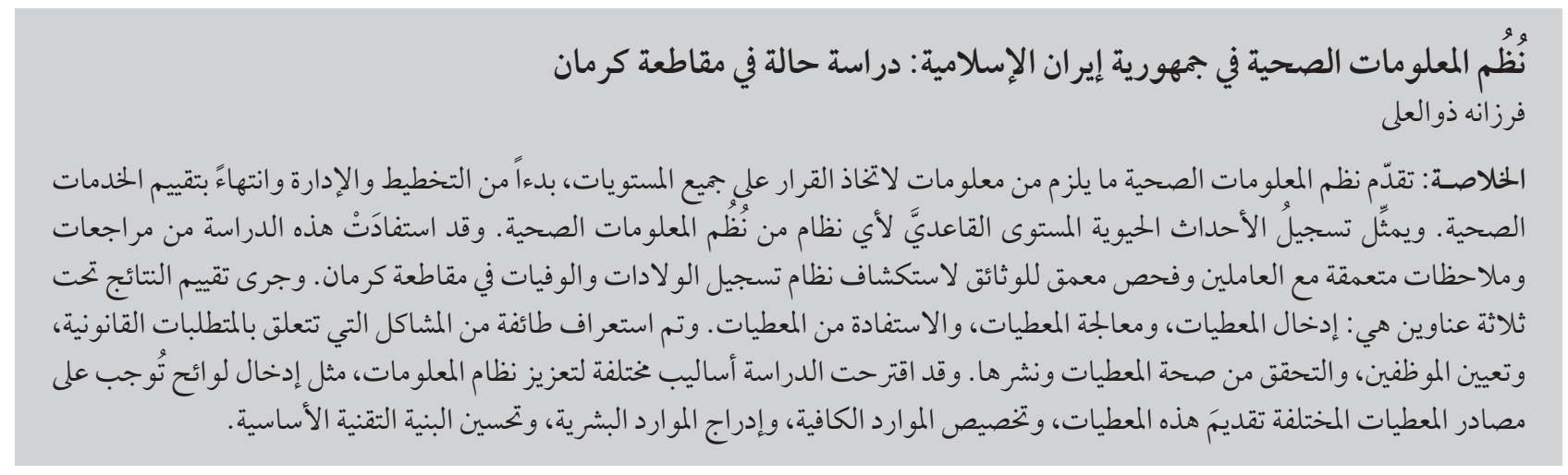

ABSTRACT Health information systems provide information for decision-making at all levels, from planning and management to evaluation of health services. Registration of vital events is the most basic level of any health information system. This case study used in-depth interviews, observations and examination of documents to explore the system of births and deaths registration in Kerman province. The findings were evaluated under 3 headings: data input, data processing and data usage. A range of problems were identified concerning legal requirements, staffing, data checking and publication of data. Different approaches are suggested to strengthen the system, such as introducing regulations to oblige different data sources to provide data and allocating sufficient resources, including human resources, and an improved technology infrastructure.

Systèmes d'information sanitaire en République islamique d'Iran : étude de cas dans la province de Kerman

RÉSUMÉ Les systèmes d'information sanitaire fournissent des données utiles à la prise de décision à tous les niveaux, de la planification et la gestion à l'évaluation des services de santé. L'enregistrement des faits d'état civil correspond au niveau le plus basique de tout système d'information sanitaire. À partir d'entretiens approfondis, d'observations et de l'examen de documents, l'étude de cas a permis d'analyser le système d'enregistrement des naissances et des décès dans la province de Kerman. Les résultats ont été évalués en fonction de trois catégories : la saisie des données, le traitement des données et l'exploitation des données. Une série de problèmes a été identifiée concernant les obligations légales, les effectifs, la vérification des données etleur publication. Différentes approches suggèrent de renforcer le système, comme par l'introduction de réglementations obligeant certaines sources d'information à fournir des données et à allouer des ressources suffisantes, notamment des ressources humaines, et à améliorer l'infrastructure des technologies.

${ }^{7}$ Regional Knowledge Hub for HIV/AIDS Surveillance, Faculty of Health, Kerman University of Medical Sciences, Kerman, Islamic Republic of Iran (Correspondence to F. Zolala: farzanehzolala@yahoo.com). ${ }^{2}$ Department of Public Health Sciences, University of Edinburgh, Edinburgh, United Kingdom.

Received: 22/11/09; accepted: 11/01/10 


\section{Introduction}

Health information systems (HIS) provide information for decision-making at all levels, from planning and management to evaluation of health services [1]. The ultimate aim is to improve the health status of individuals and populations [2]. The need for accessible, quality health data is growing in many countries and in developing countries in particular. Boerma et al. have pointed out that as financial support to developing countries increases there is an increased need to measure progress towards achieving health goals such as those of the Millennium Development Goals [3]. This can be achieved through monitoring specific health indicators.

Despite the crucial role of HIS in helping policy-makers to recognize problems and improve their health systems, most developing countries have poor HIS. To tackle this problem some developing countries have added parallel systems to their national HIS to gain better information [2]. While these systems may achieve better quality of information on specific topics, they can create problems in duplication of data and they risk damaging the cohesion of the whole HIS system [2].

The need to develop quality HIS in developing countries has beenidentified by international organizations such as the World Bank [4] and World Health Organization (WHO), who established the Health Metrics Network in 2005 as the first global partnership dedicated to strengthening national HIS [5]. Based on the WHO framework, HIS are divided into 6 components: resources, indicators, data sources, data management, information products and information use. These components are also grouped under 3 headings: input, which is concerned with HIS resources; process, which includes health indicators, data sources and data management; and outputs, which are the products and use of the information [6].
The most basic level of health data come from civil registration [7], which is the continuous, obligatory, legal process of recording vital events [8]. Registration of vital events is one of the most important priorities in human society. A birth record confirms the existence of a person, which is the first step towards protection of his/her rights to life and social rights such as freedom [9].

The aim of this study was to use the Health Metrics Network framework to identify strengths and weaknesses in the system of births and deaths registration in Kerman province.

\section{Methods}

\section{Background}

The health system in the Islamic Republic of Iran is a partnership between the medical education system and health carefacilities [10].Ineach provincethere is at least one medical science university, which is the official representative of the Ministry of Health and Medical Education (MOHME) in that province [11]. The district health network is an office under the supervision of the medical university, and is the official administrator of health and medical care in each district [12]. Health services in the rural areas are provided through "health houses", which are small health centres located in villages. Approximately $86 \%$ of the rural population are covered by health facilities [13].

There are 2 main sources of mortality data in Islamic Republic of Iran: the statistics unit under the supervision of the MOHME and the civil registry under the supervision of the Ministry of Interior. The only official source for live births data is the civil registry.

\section{Data collection}

This study was a part of a larger study carried out in 2 cities (Bam and Kerman) which are in the centre of Kerman province. Kerman is the second largest province in the Islamic Republic of Iran, located in the south-east of the country.

The data were collected from examination of documents and observations and indepth interviews with personnel working at different levels of data collection systems, including data collectors in rural and urban areas, data processors and policy-makers at the local (Bam) and provincial (Kerman) levels. Conducting interviews at the workplace enabled the researcher to obtain a better perception about problems that could affect data quality. The documents used in this research were mainly available only at the target organizations. Permission to conduct the study was obtained through the vice-chancellor of the health department in Kerman province. Collaboration with the civil registry was obtained through a letter issued from Kerman Medical University. Permission to carry out interviews at the civil registry was issued by the head of the civil registry.

\section{Results}

The results are presented under 3 headings: data input, data processing and data usage.

\section{Data input}

Data input analyses the data capture procedures. The interviews established that the civil registry was principally notified of births and deaths by people's testimony on a birth or death certificate. This means that there is no direct reporting from any official health system such as hospitals to the civil registry. Apart from people's testimony, the only way that the civil registry is notified about deaths is reports sent from semi-private cemeteries. Regarding people's testimony it was reported that many people postponed notifying the civil registry of deaths and births until they needed it for a specific reason, for example school enrolment, insurance or inheritance claims. This was more likely to happen in 
rural and remote areas where residents had to travel long distances to access the local offices of the civil registry. The problem was compounded by the fact that the penalty for failure to register or for late registration is only a small fine, with inadequate enforcement of the law. In addition, deceased people with no property are unlikely to be registered at the civil registry

Although the medical university and its data collection system in the rural areas had a better coverage of vital data in comparison with the civil registry, it had its own deficiencies. As mentioned earlier, the health system in the Islamic Republic of Iran covers only $86 \%$ of rural areas, which means that even with complete data collection $14 \%$ of the rural population are not covered by the system.

In urban areas, the following are required to send data to the statistics unit of the health network [14]: health facilities (private and public), forensic medicine departments and cemetery offices. However the study interviews revealed that the medical university often failed to gain data from the forensic medicine department and from the private cemetery office. Furthermore, there was inconsistency in data transfers from private hospitals between different cities. Another matter was that semiprivate cemetery offices and hospitals are required to send their data in a different format to that of the vice-chancellor of the treatment department in Kerman province.

\section{Data processing}

Data processing addresses the question of how the data are processed and by whom. The interviews and documents showed that the original data were transmitted in written form. At the medical university, the data were integrated manually at the peripheral level before being sent to the health network for computerization.

A number of problems with data processing were identified. The software used for data entry at the civil registry was different and incompatible with that used at the medical university. The organizations used two different version of the International Classification of Diseases for coding of mortality data. The medical university had a shortage of computers at some levels. There was limited technical support for the staff using computers. While both organizations used the data entry software for data checking, there was little manual data checking for errors. Feedback on the quality of the data was rarely conducted.

The study also revealed that there were inadequate staff of the appropriate academic level working with data at the medical university and the civil registry. Those who worked with data at the medical university complained of having to do other tasks beside data collection and of a high turnover of staff working in data processing. In addition, there was limited pre-service or on-the-job training of staff. This was exacerbated by an absence of guidelines explaining the data collection procedures in detail. Another problem mentioned were delays in data sending from the peripheral levels such as villages to districts and from districts to the centre of the province.

\section{Data usage}

Three items concern data usage: data analysis, data availability and policymakers' views. Our analysis of documents found that the only publication produced by the civil registry was one detailing the total number of vital events at the national level. There was also an annual publication of deaths produced by the Ministry of Health. Regarding the availability of data there were some limitations at both organizations, which were rooted in limitations of data storage or technology. Interviews with policymakers showed that they perceived the main problems as poor data quality, no guidelines for data collection, lack of forward planning for health issues in general and no incentives to use the data.

\section{Discussion}

The results of this study found that there were a range of problems in the HIS for collecting vital data in the civil registry and in the medical science university of Kerman province.

These started with poor performance in data capture, due to lack of coordination and collaboration of data sources in sending the data to the target organizations, and inadequate rules and regulations or enforcement of regulations concerning the reporting of births and deaths. Coordination and collaboration are important factors in ensuring that data are transferred between organizations in a consistent manner [15].

Next there were problems with data handling, such as transferring paper data to the upper levels of the system, which did not appear to be an efficient method of data transfer [16]. In Pakistan, for example, the data from the peripheral levels are sent directly to the district level [17]. This method, however, is not the best one from the standpoint of speed, quality and accessibility. However, it may still be better than the method employed in the Islamic Republic of Iran. This is because the Pakistani method is likely to be faster [16] and it also reduces the errors that might happen during collation of the data.

Lack of compatibility of software and data coding used at the medical university and the civil registry also impeded the ability of technology to share and match the data with other data sources. This problem can lead to duplication of data and can decrease the accuracy of data [18]. The WHO framework advocates using software programs and systems which are compatible with each other at different levels [6].

The quality of data collection was also likely to be jeopardized by deficient data checking, inadequate human resources and low data usage. It has been pointed out that incorrect coding and mistakes in the entry of data in the correct fields are frequent problems 
in developing countries [19]. Limited data checking was also linked to low data usage by policy-makers. If data are utilized, they will be checked and feedback on data will be sent to data collectors and processors. It has been noted that in developing countries there are few opportunities to give feedback to data processors and data collectors to improve the quality of data [19].

The current study found that staff in data collection departments were often under-qualified. Recruiting staff with appropriate academic qualifications at different levels of the data collection system is recommended to improve the quality of data [2]. However, if data collection and processing tasks are delegated to health care providers, medical staff become overburdened and will view this as an extra and unwelcome task [6].

Low morale among staff was also identified in this survey. Job insecurity and high staff turnover are discouraging for recently graduated staff, and may lead to poor morale which affects their quality of work [20]. High turnover of HIS staff was observed in studies carried out in Swaziland [21] and Afghanistan [22]. Training is needed at all levels of a data collection system and should include policy-makers in order to increase their knowledge about the implications of data usage and interpretation on decision-making. On the other hand, data personnel should be aware of managers' interests and needs. This will lead to improved data usage [23].

The lack of guidelines for data processing found in this surveyhindered the availability of a clear and straightforward definition of the data collection strategy and how indicators should be collected. This may have caused duplication of work and overburdening of staff. Introducing guidelines clarifies the objectives of data collection and enhances data usage, particularly when policy-makers are involved in these processes [23]. Promoting guidelines was recognized as an important fac- tor in strengthening the quality of the information system in Mexico [19,24].

Possible delays in sending the data from the peripheral branches at the civil registry and regular delays in sending the data to the medical university were reported in this study. This can be traced back to the lack of strong regulations and inadequate management, high workload on personnel and also low data usage in decision-making. It is suggested that the information for managers should be available on a daily basis [6].

Use of aggregated data can reflect low data usage at the provincial and district level. Inadequate data usage at the local level reflects a number of problems. One of them is the centralized structure of the Iranian health system in which key decisions are made at the national level and the local levels do not have an important role in decisionmaking [25-27]. Furthermore, lack of an effective and accurate health system was mentioned in interviews as another obstacle to utilizing the data. This reflects the lack of a culture of data usage in the Islamic Republic of Iran. The deployment of data has a direct correlation with the quality of data [23]. If data are of poor quality, they are unlikely to be utilized. If low quality data are collected, they are likely to mislead policy-makers [28]. Promoting a system of incentives for data usage is likely to increase data usage [23].

Sending the same data in different formats is a tedious job. Having a statistics unit in individual departments is a waste of time and resources and leads to duplication of data. Establishing a powerful and central statistics unit could reduce duplication, increase the accuracy of data collection and even bring about greater availability of health information.

\section{Conclusion}

This study highlighted some ways in which the HIS in Islamic Republic of
Iran can be strengthened. It takes the efforts of policy-makers to decide which parts of the system need to be improved and which parts should be altered. The results of this review suggested different approaches to strengthen the system such as introducing appropriate rules and regulations to oblige different data sources to provide the data; allocating sufficient resources, including human resources and appropriate staff training; and having a strong communication infrastructure to increase the speed and accuracy of data collection. Better supervisory activities should be in place to ensure that the data collection procedures are on track and that data checking is undertaken by competent staff. Using compatible software in different organizations would not only provide more complete data transfer but also improve the quality of data through data cross-checking. Finally, a culture of data usage should be encouraged by the government at all levels including the national, provincial and districts levels. Introducing guidelines explaining the indicators for short-term and long-term quality monitoring activities and establishing a central statistics unit in the Islamic Republic of Iran would be helpful in improving the quality of health data.

\section{Acknowledgements}

This project was financially supported by Kerman Medical University. The author recognizes the good collaboration of Kerman Medical University and Bam health network by facilitating access for fieldwork. The author would like to acknowledge and thank her supervisor Dr John Forbes for his professional guidance and encouragement. The author also acknowledges the contribution by staff of Kerman Medical University and of Bam health network for giving their time to be interviewed. 
1. Hurtubise R. Managing information systems, concepts and tools. In: Lippeveld T, Sauerborn R, Bodart C, eds. Design and implementation of health information systems. West Hartford, Connecticut, Kumarian Press, 1984.

2. Lippeveld T. Routine health information systems: the glue of $a$ unified health system. Paper presented at the The RHINO Workshop on Issues and Innovation in Routine Health Information in Developing Countries, March 14-16, 2001. The Bolger Center, Potomac, Maryland, 2001 (http://www.cpc. unc.edu/measure/publications/html/rhino2001/workshopagenda.html\#themel, accesed 15 June 2011).

3. Boerma JT, Stansfield SK. Health statistics now: are we making the right investments? Lancet, 2007, 369:779-786.

4. World development report 1993. Investing in health. Washington DC, World Bank, 1993

5. Health Metrics Network. Assessing the national health information system: an assessment tool, version 4.00. Geneva, World Health Organization, 2008.

6. Health Metrics Network. Framework and standards for country health information systems. Geneva, World Health Organization, 2008

7. Kane $R$ et al. Uses of routine data sets in the evaluation of health promotion interventions: opportunities and limitations. Health Education, 2000, 100:33-41.

8. Department of Economic and Social Affairs. Principles and recommendations for a vital statistics system, revision 2. New York, United Nations, 2001 (ST/ESA/STAT/SER.M/19/Rev.2).

9. Horton R. Counting for health. Lancet, 2007, 370:1526.

10. Mesdaghinia A. Health and welfare systems development in the 21st century. Proceedings of the Third Global Symposium, 6-8 November 2002. Kobe, Japan, World Health Organization Centre for Health Development, 2002.

11. World health day 2001. Country profiles: Islamic Republic of Iran. World Health Organization [online factsheet] (http://www. emro.who.int/mnh/whd/CountryProfile-IRA.htm, accessed 15 June 2011).

12. Review of health information systems (HIS) in selected countries. III. The Islamic Republic of Iran. World Health Organization [online document] (http://www.who.int/entity/healthmetrics/ library/iran_05apr.doc, accessed 15 June 2011).

13. Naghavi $\mathrm{M}$ et al. [The changes in the health features of rural residents in Iran, 1st ed.]. Tehran, Islamic Republic of Iran, Barge Rezvan, 2005 [in Farsi].

14. Naghavi M. [Mortality features in 23 province in Iran in 2003]. Tehran, Islamic Republic of Iran, Ministry of Health and Medical Education, 2005 [in Farsi].

15. Lippeveld T, Sapirie S. Approaches to strengthening health information systems. In: Lippeveld T, Sauerborn R, Bodart C, eds. Design and implementation of health information systems. Geneva, World Health Organization, 2000.
16. Shrestha.L, Bodart C. Data transmission, data processing and data quality. In: Lippeveld T, Sauerborn R, Bodart C, eds. Design and implementation of health information systems. Geneva, World Health Organization, 2000.

17. National health management information system (HMIS) (Pakistan). Government of Pakistan [website] (http://www.pakistan.gov.pk/, accessed 15 June 2011).

18. Zhang $Y$ et al. An investigation into health informatics and related standards in China. International Journal of Medical Informatics, 2007, 76:614-620.

19. Chaulagai $\mathrm{CN}$ et al. Design and implementation of a health management information system in Malawi: issues, innovations and results. Health Policy and Planning, 2005, 20:375384.

20. Dasgupta S. Employment security: conceptual and statistical issues. In: Diane-Gabrielle Tremblay Employment security as a determinant of health. Geneva, International Labour Office, 2001

21. Report on strengthening national health information systems. Workshop on the use of geographical information system healthmap. Harare, Zimbabwe, 1-4 July 2002. Brazzaville, World Health Organization Regional Office for Africa, 2002 (http://www.equinetafrica.org/bibl/docs/WHOehs02.pdf, accessed 15 June 2011).

22. Health Metrics Network. Health information system assessment: country report. [Afghanistan] Health Information System: Review and Assessment [June, 2007]. Kabul, Afghanistan, Ministry of Public Health, 2007 (www.paris21.org/sites/default/files/ afghan-HMNassessment-2007.pdf, accessed 21 July 2011).

23. Sauerborn R. Using information to make decision. In: Lippeveld T, Sauerborn R, Bodart C, eds. Design and implementation of health information systems. Geneva, World Health Organization, 2000

24. Duran-Arenas L et al. The development of a quality information system: a case study of Mexico. Health Policy and Planning, 1998, 13:446-458.

25. Gladwin J, Dixon RA, Wilson TD. Rejection of an innovation: health information management training materials in east Africa. Health Policy and Planning, 2002, 17:354-361.

26. Sauerborn R, Lippeveld T. Introduction. In: Lippeveld T, Sauerborn R, Bodart C, eds. Design and implementation of health information systems. Geneva, World Health Organization, 2000.

27. The role of contractual arrangements in improving health sector performance. Report on a regional meeting, Cairo, Egypt, 18-20 April 2005. Cairo, World Health Organization Regional Office fo the Eastern Mediterranean, 2005 (WHO-EM/PHP/034/E).

28. AbouZahr C, Adjei S, Kanchanachitra C. From data to policy: good practices and cautionary tales. Lancet, 2007, 369:10391046 